1 Figueroa J E, Densen P. Infectious diseases associated with complement deficiencies. Clin Microbiol Rev 1991; 4: 359-95.

2 Ross S C, Densen P. Complement deficiency states and infection: Epidemiology, states and infection: Epidemiology, and other infections in an immune deficiency. and other infections in an im

3 Agnello V. Lupus diseases associated with hereditary and acquired deficiencies of complement. Springer Semin Immunopathol 1986; 9: 161-78.

4 Johnson C, Densen P, Wetsel R A, Cole F S, Goeken N E, Colten H R. Molecular heterogeneity of $\mathrm{C} 2$ deficiency. $N$ Engl $\mathcal{M}$ Med 1992; 326: 871-4.

5 Johnson C, Densen P, Hurford R K, Colten H $R$, Wetsel R A. Type 1 human complement C2 deficiency; A 28-base pair gene deletion causes skipping of exon 6 during RNA causes skipping of exon 6 during RNA

6 Rendall J R S. Vasculitis with probable familial C2 deficiency (Case 1) and Systemic lupus erythematosus with familial C2 deficiency (Case 2). Proc R Soc Med 1977; 70: 733-4.

7 Brout C, Clauvel J-P, Peltier A, Sasportes M, Seligmann $M$. Déficit génétique du deuxième constituant du complément: étude de trois nouvelles observations. Ann Méd interne 1978; 129: 637-41.

8 Day N K, Geiger H, McLean R, Michael A, Good R A. C2 deficiency. Development of lupus erythematosus. $f$ Clin Invest 1973; 52: 1601-7.

9 Roberts J L, Schwartz M M, Lewis E J. Hereditary $C 2$ deficiency and systemic lupus erythematosus associated with severe glomerulonephritis. Clin Exp Immunol 1978; 31: $328-38$.

\section{Eosinophilic fasciitis in a father and son}

Eosinophilic fasciitis ${ }^{12}$ is a rare syndrome consisting ${ }^{5}$ of: (1) localised skin involvement; (2) pronounced thickening of the subcutaneous fascia; (3) absence of visceral changes and Raynaud's phenomenon; (4) peripheral blood eosinophilia, hypergammaglobulinaemia raised ESR and (5) beneficial response to steroids. Some authors believe it is a variant of scleroderma whilst others believe it is a separate disease. ${ }^{34}$ We report two cases of eosinophilic fasciitis occurring in a father and son with clinical and laboratory evidence of the disease, presenting nineteen years apart.

Patient 1, a 19 year old man, presented in 1969 with a one year history of aching in the small joints of his hands and feet and tightness of the skin over his forearms and legs. Physical examination revealed boardlike skin over the limbs, hands and trunk. His ESR was $61 \mathrm{~mm}$ in the first hour and his white cell count was $25 \times 10 \% / \mathrm{dl}$ with $80 \%$ eosinophils. The SGOT was normal and an extensive search for occult parasites was negative. He had a normal chest radiograph and barium swallow.

A full thickness skin biopsy was performed and this was reported to show changes of dermatomyositis. Review of the biopsy was diagnostic of eosinophilic fasciitis. It showed broad bands of collagen extending across and deep into the subcutaneous fat with numerous areas of inflammation. The infiltrates consisted of plasma cells, lymphocytes and eosinophils. Similar extensive infiltrates were found throughout the fascia.

A diagnosis of 'dermatomyositis with scleroderma' was made and the patient was started on prednisolone $45 \mathrm{mgs}$ daily. The skin tethering rapidly improved and the peripheral eosinophilia resolved. $\mathrm{His}$ prednisolone was withdrawn after three years and when seen recently his skin was normal.

Patient 1 had two sons, one of whom has coeliac disease (tissue type: HLA A3, A32, B8, B35, BW6, CW4, CW7). The other presented in July 1988 at the age of 14 years with a six month history of stiffness of his fingers and tightness of the skin over his arms and legs. There was no history of Raynaud's phenomenon and no problems with his swallowing, chest or digestion.

On examination he had woody, tethered oedematous skin over his arms and legs. He had flexion contractures of the MCP joints bilaterally and his elbows and wrists were immobile.

Laboratory tests showed an $\mathrm{Hb} 13 \mathrm{~g} / \mathrm{dl}$, wcc $8.7 \times 10^{9} / \mathrm{dl}$ with $16 \%$ eosinophils, ESR $16 \mathrm{mms}$ per hour. His electrolytes, C3, C4 levels were normal. His IgG was $20.5 \mathrm{~g} / \mathrm{l}$, IgA and IgM normal. ANA and anti-Scl 70 were negative, chest and hand radiographs were normal.

A full thickness skin biopsy revealed a normal epidermis; almost all the glandular elements were tightly bound with collagen. There was local infiltration by lymphocytes and plasma cells. The fascia was infiltrated with numerous lymphocytes and occasional plasma cells. The cells extended between the muscle fibres-all the changes suggested eosinophilic fasciitis.

He was started on prednisolone $30 \mathrm{mgs}$ daily and clinically he improved together with the disappearance of his eosinophilia and hypergammaglobulinaemia. $\mathrm{He}$ is presently on prednisolone $4 \mathrm{mgs}$ alternate days but his skin has not yet completely returned to normal.

HLA typing was performed on the father and son, which showed the son inherited A3, B52, Cw null haplotype from his father.

The two patients described appear to be the first cases of eosinophilic fasciitis involving a father and son. Both had the characteristic features and responded to corticosteroids. The father initially eluded diagnosis as the disease had not yet been described by Shulman. ${ }^{2}$

The only other familial cases of eosinophilic fasciitis is the report of siblings with identical HLA genes. ${ }^{6}$ Our patients, however, had completely different haplotypes from those described.

We feel eosinophilic-fasciitis probably has a multifactorial aetiology with a combination of genetic and environmental factors playing a role.

ROSENFELD M A STODELL Department of Rheumatology, Luton and Dunstable Hospital NHS Trust, Lewsey Road, Luton LU4 ODZ, United Kingdom

Correspondence to: Dr Stodell

1 Shulman L E. Diffuse fasciitis with hypergammaglobulinaemia and eosinophilia: a new syndrome? (abst) $\mathcal{F}$ Rheumatol 1974; 46 (Suppl 1): 00-00.

2 Shulman LE. Diffuse fasciitis with eosinophilia: a new syndrome. Arthritis Rheum 1977; 20 (Suppl): S205.

3 Maddison P J. Mixed connective tissue disease, overlap syndromes, and eosinophilic fasciitis. overlap syndromes, and eosinophil

4 Doyle J A, Connolly S M, Winkelman R K. Cutaneous and subcutaneous inflammatory Sclerosis syndrome. Arch Dermatol 1982; 118:

5 Bennet R M, Herron A, Keogh L. Eosinophilic fasciitis. Ann Rheum Dis 1977; 36: 354-9.

6 Thomson G T D, MacDougall B, Watson P H, Chalmers I A. Eosinophilic fasciitis in a pair of siblings. Arthritis and Rheumatism 1989; 32: 96-99.

\section{Massive eosinophilic synovitis and reactive arthritis associated with filarial infection}

Eosinophils are infrequently recovered from either the synovial fluid or the synovial membrane. ${ }^{1}$ We report a case of reactive arthritis and massive synovial fluid eosinophilia associated with filarial infection.

A 26 year old African-American woman was admitted to hospital with acute left ankle arthritis. She had resided in the United States of America for four years. Eight months before she was seen, however, she had returned to Nigeria for four weeks. Three months before admission she experienced right wrist swelling that resolved spontaneously within three days. Similarly, transient right ankle swelling occurred one month before presentation.

On admission, the patient denied any history of constitutional, gastrointestinal or other nonarticular symptoms. Physical examination was normal except for left ankle swelling. Complete blood count revealed $9200 \mathrm{WBC} / \mathrm{mm}^{3}$ with a differential of $20 \%$ neutrophils, $30 \%$ lymphocytes, and $47 \%$ eosinophils. The erythrocyte sedimentation rate (ESR) was 73. Routine serological studies, including ANA, RF, VDRL, hepatitis $B$ surface antigen, and serum concentrations of complement proteins C3 and $\mathrm{C} 4$ were negative or normal. Analysis of synovial fluid aspirated from the left ankle revealed $56000 \mathrm{WBC} / \mathrm{mm}^{3}$, with a differential of $8 \%$ neutrophils, $4 \%$ lymphoctytes, $15 \%$ monocytes and $73 \%$ eosinophils (absolute eosinophil count $40880 / \mathrm{mm}^{3}$ ). A radiograph of the left ankle was normal. Cultures of synovial fluid, blood, urine, pharynx, rectum and cervix were negative. Stool specimens showed Entamoeba histolytica, Trichuris trichuria, and the noninvasive pathogen Endolimax nana. Histopathological analysis of a synovial biopsy specimen revealed granulation tissue with numerous eosinophils within the synovial tissue. Parasitic organisms could neither be seen nor cultured. Treatment was initiated with doxycycline, amoxicillin, mebendazole and iodoquinol. Despite the completion of appropriate courses of antibiotics and the elimination of pathogens from stool cultures, left ankle swelling persisted. Subsequently, a panel of parasitic serologies was obtained, and revealed very high serum titres of antifilarial antibodies (>1:2048), with insignificant titres to other invasive parasites, including Entamoeba histolytica. Four months after her initial presentation her ankle arthritis persisted. Treatment was initiated in hospital with diethylcarbamazine. On her last clinic visit before being lost to follow up, the patient no longer had joint swelling.

Reactive arthritis ( $\operatorname{ReA})$ has been associated with a variety of infectious agents. In the West, the most common organisms are obligate or facultative intracellular bacteria; such as Chlamydia trachomatis. ${ }^{2} \operatorname{ReA}$ associated with parasitic infection has been reported, but is rare. Filariasis is the most commonly implicated aetiological agent. $^{3}$ Indeed, articular manifestations may be seen in up to $10 \%$ of patients with filariasis. ${ }^{4}$ Approximately two thirds of the patients develop a monarticular arthritis affecting the 
large joints of the lower extremity. Synovial fluid eosinophilia has been noted, but only infrequently. ${ }^{4}$ Although the arthritis is selflimited in most patients, it often recurs and may eventually become chronic. In contradistinction to ReA associated with bacterial infections, the majority of patients have no constitutional symptoms or other signs of filariasis. In this patient, the clinical picture was most consistent with $\operatorname{ReA}$ associated with filariasis. Although she did have other parasites in her stool, their association with the arthritis is militated against by the lack of gastrointestinal symptoms as well as the failure to respond to specific therapy.

Eosinophils are infrequently noted in the synovial fluid. When present, they typically constitute less than $2 \%$ of leukocytes. ${ }^{5}$ More pronounced synovial fluid eosinophilia has been reported in association with various rheumatological, infectious, allergic and malignant diseases. However, absolute synovial eosinophil counts above $10000 / \mathrm{mm}^{3}$ are exceedingly rare, having been reported to date in one case of idiopathic transient synovitis, ${ }^{6}$ and two cases of Lyme disease.

It might be unexpected for eosinophilia to be associated with $\mathrm{ReA}$. The antigen specific $T$ cells in the synovium of $\operatorname{ReA}$ patients described to date have been predominantly of the $T_{H} 1$ phenotype, which secrete primarily IL-2 and IFN- $\gamma$. $^{2}$ On the other hand, eosinophilia is more commonly associated with activation of $T$ cells of the $T_{H} 2$ phenotype, which produce primarily IL-4 and IL-5. Because IL-5 promotes the differentiation as well as the survival of eosinophils, it may be critical to conditions associated with eosinophilia.?

This report demonstrates that $\operatorname{ReA}$ associated with filariasis may be associated with massive synovial eosinophilia. This association raises the hypothesis that in some instances, in particular those associated with eosinophilia, ReA might be mediated by $\mathrm{T}$ cells of a $\mathrm{T}_{\mathrm{H}} 2$ phenotype.

CHARLES LUBIANCA KOHEM SANDRA VASQUEZ KRISTIANSEN ARTHUR FRANCIS KAVANAUGH Rheumatic Diseases Division, Department of Internal Medicine The University of Texas, Southwestern Medical Center 5323 Harry Hines Blvd, Dallas, Texas 75235-8884

1 Schumacher H R. Synovial fluid analysis. In Kelley W N, ed. Textbook of rheumatology. Rel W B Sanders; 1993: 562-70. Kingsley G, Sieper J. Current perspectives in reactive

3 Patey O, Bouhali R, Breuil J, Chapius L, Courillon-Mallet A, Lafaix C. Arthritis assaciated with strongyloides stercolis. Scand F Infect Dis 1990; 22: 233-6.

4 Bocangera T S. Rheumatic Manifestations of Parasitic Diseases. In: Espinoza L, ed. Infections in the rheumatic diseases. London: Grune and Stratton; 1988: 243-6

5 Kay J, Eichenfield A H, Athreya B H, Doughty R A, Schumacher H R. Synovial fluid eosinophilia in Lyme dsease. Arthritis Rheum 1988; 31: 1384-9.

6 Luzar M J, Friedman B M. Acute synovial fluid eosinophilia. f Rheumatol 1982; 9: 961-2.

7 Robinson D S, Hamid Q, Ying S, et al. Predominant TH2-like bronchoalveola Predominant Engl fMed 1992; 326: 198-304.

\section{MATTERS ARISING}

\section{Antiperinuclear and anti- RA33 antibodies in juvenile chronic arthritis}

Gabay et al recently reported results of their study on the occurrence of antiperinuclear (APF), anti-keratin, and anti-RA33 antibodies in juvenile chronic arthritis (JCA). These data differ from ours, regarding APF and anti-RA33. ${ }^{2}$ We reported that a third of patients with juvenile rheumatoid arthritis (JRA) were tested positive for APF in an undiluted serum, compared to only $1.6 \%$ in this study. Although several hypotheses may explain this difference, we believe that a major factor was the difference in criteria used to define APF positivity. We have found that identifying five positive cells on a slide is sufficient to define positivity without decreasing the specificity of APF assay significantly in children with JRA. Reviewing our data, we found that using the criteria of Gabay et al (that is, APF positivity only when $10 \%$ or more of cells are positive), 'APF positivity' was detected in only $8 \%$ of our patients. It is unclear whether this figure describes the 'true positivity' of APF in JRA. We believe that using less-strict criteria would enable us to detect more APF-positive cases without lowering the specificity of the test in children with JRA.

The data by Gabay et al and ours were also at variance regarding anti-RA133 occurrence. Although the rates were similar in patients with polyarticular disease, we found that $67 \%$ of pauciarticular JRA patients had anti-RA33, compared with only $2 \%$ in the study by Gabay et al. Again, many hypotheses may be entertained to explain this difference, such as the sensitivity of the assay, differences in populations, etc. We believe it may reflect the differences in defining JCA and JRA, which is most noticeable in cases of pauciarticular-onset. ${ }^{4}$

In conclusion, these major differences in the occurrence of APF and anti-RA33 in children with chronic arthritis may be 'artificial'. It emphasises the need to form universal criteria regarding the definition of positivity of APF in children, and classification of chronic arthritides in childhood.

GIDEON NESHER VIRGINIA K WILSON TERRY L MOORE THOMAS G OSBORN VAUGHN E HANNA Saint Louis University School of Medicine R215 Doisy Hall Saint Louis, MO 63104, USA

1 Gabay C, Prieur A M, Meyer O. Occurrence of antiperinuclear, anti-keratin, and anti-RA33 antibodies in juvenile chronic arthritis. $A n n$ Rheum Dis 1993; 52: 785-9.

2 Nesher G, Moore T L, Grisanti M W, ElNajdawi E, Osborn T G. Antiperinuclear factor in juvenile rheumatoid arthritis. $A n n$ Rheum Dis 1992; 51: 350-2.

3 Wilson V K, Osborn T G, Hanna V E, Moore T L. Presence of RA33 in pauciarticularonset juvenile rheumatoid arthritis. Arthritis Rheum 1993; 36: S209.

4 Laxer R M. What's in a name: the nomenclature of juvenile arthritis. $\mathcal{F}$ Rheumatol 1993; 20 (suppl 40): 2-3.
Author's REPLY: Nesher et al suggest that the low prevalence of antiperinuclear and anti-RA 33 antibodies in our study was mainly related to the criteria used to define APF positivity and a subset of patients with pauciarticular onset juvenile chronic arthritis (JCA)

Our assay for APF has already been validated in patients with rheumatoid arthritis. The prevalence of APF was in accordance with those published elsewhere and the specificity was higher than $90 \% .{ }^{1} \mathrm{We}$ therefore think that the low prevalence of APF in our study does not reflect a lack of sensitivity of our assay. In addition, other investigators who did not use the same methodology as ours, also found a very low prevalence of APF in a large cohort of JCA patients. ${ }^{2}$ Finally, it should also be mentioned that the percentage of APF positive sera found by Nesher $e^{2} \mathrm{al}^{3}$ was not so impressive, as only one third of their patients had a positive result with their assay. In addition the occurrence of positive APF falls to $11 \%$ when sera were diluted 1:10.

The specificity of APF for the diagnosis of RA is well accepted; however, positive results have also been reported in other conditions. We and others ${ }^{5}$ have demonstrated that considering a positive result when $10 \%$ or more of the cells show typical staining increases the specificity without significantly decreasing the sensitivity of the test. Nesher et al compared their results in JCA with those found in sera from normal controls and found a good specificity. They also reported positive results in up to $17 \%$ of the children with systemic lupus erythematosus (SLE). In our opinion their results in JCA should also be compared to those found in the patients with SLE to assess the specificity of their assay.

With the exception of a subset of patients with RF-positive polyarticular onset, we found that prevalence of anti-RA 33 antibodies was rather low in JCA patients. Again, we already validated our assay in previous studies. ${ }^{6}$ Nesher et al suggest that the low percentage of anti-RA 33 antibodies in the sera from our children with pauciarticular onset reflects the differences in defining this subset of patients. We do not agree with them, because the criteria for pauciarticular onset JCA in the ACR or EULAR/WHO classifications are almost the same. This subset of patients includes a group of young children-mainly girls - with four or less joints affected at onset, a high prevalence of positive antinuclear antibody (ANA) test and ocular complications. As described in our paper, the age of onset, articular features, sex ratio, and percentage of positive ANA test clearly show that our children fulfil both the European and American criteria for the classification of pauciarticular onset JCA (or JRA). The evolution of articular features may, however, vary in this subgroup of patients. Some have persistent pauciarticular involvement, whereas others convert to polyarticular disease. The higher prevalence of anti-RA 33 antibodies reported by Wilson et $a l^{7}$ could be related to the heterogeneity of this subset of JCA and/or to the few cases included in their study (12 patients)

Although anti-RA 33 antibodies have previously been reported to be highly specific for the diagnosis of RA, we also found this antibody in high percentages in other conditions, such as mixed connective tissue disease and SLE. ${ }^{6}$ Unfortunately, Wilson et 